ISAHP 1996 Vancouver, Canada, July 12-15, 1996

\title{
AN APPLICATION OF THE ANALYTIC HIERARCHY PROCESS FOR THE BOSPHORUS CROSSING IN ISTANBUL
}

\author{
Tülay Kúlınçaslan ${ }^{1}$ and Birsen Karpak ${ }^{2}$ \\ ${ }^{\prime}$ Department of Urban and Regional Planning, \\ Istanbul Technical University, Taksim 80191, İstanbul, TURKEY \\ ${ }^{2}$ Department of Management, Youngstown State University \\ Youngstown, Ohio 44555, LSA \\ FR110901 at YSUB.YSU.EDU
}

\begin{abstract}
In this paper, itineraries in a transport system will be investigated to help city authorities to prioritize alternative routes to improve them. In İstanbul, most commuters have to select a combination of transport modes for crossing the Bosphorus, these will be termed "Itineraries" in the paper. Transport authorities who aim to provide the most efficient transportation system for commuters, have to consider passenger preferences as well as environmental pollutants of the different transport services. Thirty-four alternative itineraries are prioritized based on time, comfort, cost and pollution criteria, using Analytic Hierarchy Process(AHP) a multicriteria decision support system. Results indicate that itineraries which provide service frequency, with moderate comfort level and less environmental pollution have priorities.
\end{abstract}

\section{Introduction}

The city of İstanbul has witnessed a rapid growth in the past; the population increased i.om three million in 1970 to ten million in 1994. In addition to the population increase, the urban land use pattern has drastically changed (İstanbul Master Plan, 1995).

The problems became more complicated with the sudden growth of residential areas and new locations of industrial, commercial and financial centers. Istanbul was transformed from a monocentric to a polycentric city following the expansion of the city boundries and the development of communication systems. This transformation will continue in the future (Dökmeci and Berköz, 1994)

In İstanbul, the structure of the city fabric and the organization of urban transport are closely related. The expansion of the city in certain directions has dominated the extension of transport services to these areas and, in relation, the development of principal transport itineraries has accelerated urban growth around them. In the process of urban development which side of this interactive relationship will dominate over the other is determined to a great extent by the type and extent of capital entering into the transportation and the construction sector.

Nowadays, the transport system is inadequate to supply the existing travel demand. In order to increase the accessibility in the city, Light Rail Transport (LRT) facilities have been added to the system. Maritime transportion will be improved in the near future. An underground railway system (Metro) is under construction. 
Construction project decisions are generally made by elected bodies. Municipalities have to decide how to allocate funds and to satisfy public expectations which is their main goal. At this stage, a quantitative method would be useful for decision makers.

In the paper, a quantitative method, The Analytic Hierarchy Process (AHP), has been tested as a multicriteria decision approach on a specific problem. Cross-Bosphorus traffic is one of the major problems for which the municipalities have to bring urgent solutions. The existing commuting systems between the eastern. and western. sides of the city are currently inadequate due to the absence of effective transport services on the Bosphorus (Kulınçaslan, 1995).

In order to provide adequate transportation, central and local governments have made investments on several projects. The construction of the first Bosphorus Bridge was finalized in 1973 and the second bridge in 1984. Currently, local and central authorities are in the process of decision making for new infrastructure investments in order to improve the accessibility and thus to decrease the difficulties occured at the Bosphorus crossing. Local and central decision makers in government have to decide whether to build another bridge or construct a tunnel. Improvement of the existing transport facilities is yet another approach.

The city of İstanbul policy makers' approaches have been briefly explained in the Introduction. The available itineraries for first bridge Bosphorus-crossings are explained in the second section. The available alternatives of the first Bosphorus bridge have been examined by the AHP and brief description of the AHP is given in the third section. The goal, selected criteria and alternative itineraries have been structured in a hierarchical manner and explained in the fourth section.

Prioritization of the alternatives by selected criteria have been presented in the fifth section. Experts in the field of transportation and environmental pollution directed the study. Intensity levels and relative weights of the criteria were based on professional opinions. Results are presented in the sixth section The last part of the paper covers the conclusion and suggestions.

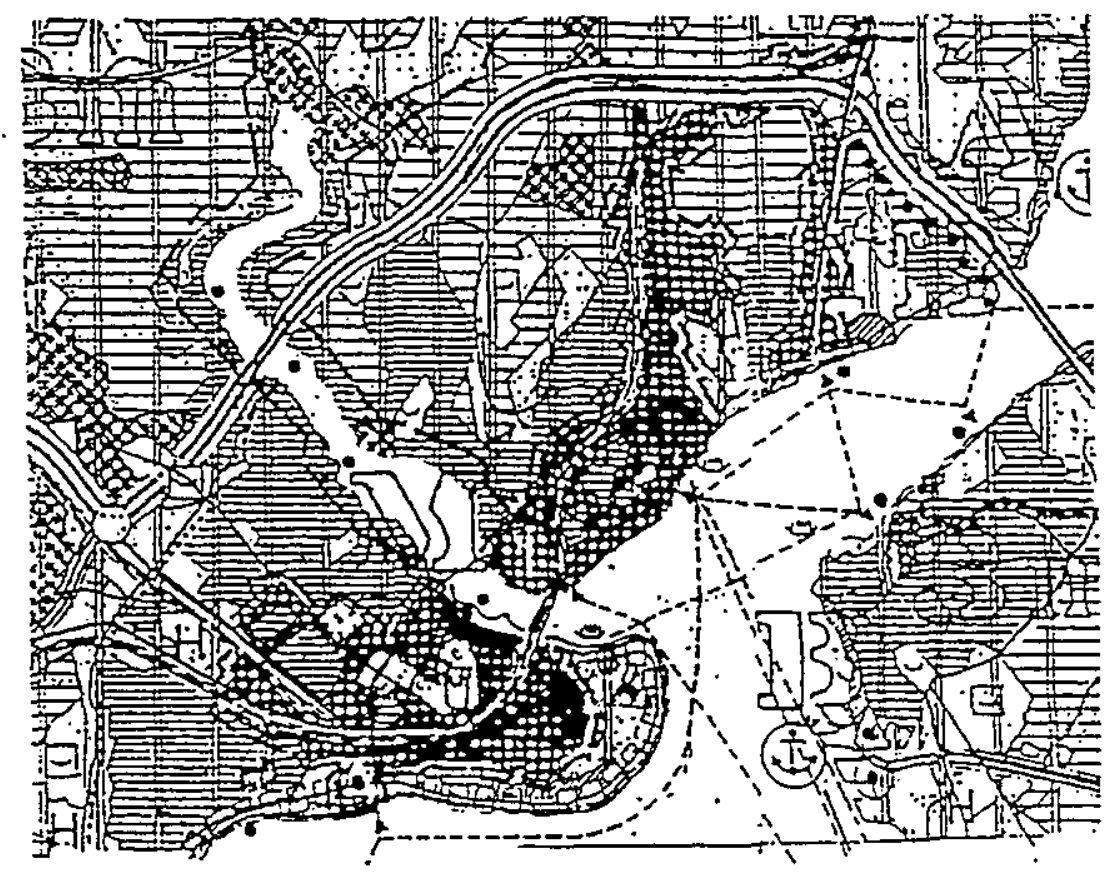

Figure 1: Linear Expansion of the Istanbul CBD (Dökmeci and Berkïz, 1994) 


\section{The Bosphorus Crossing}

There is an imbalance between active population and employment on two sides of the city of İstanbul (16). Since a large number of places of employment are Iocated on the European side and residential areas are densely located on the Anatolian side; an active population has to commute from the Anatolian side to the European coast (See Figure 2 and 3).The number of commuters between the two shores of İstanbul increased $20 \%$ in 1990, 35\% in 1995 (İstánbul Master Plan, 1995).

The public transport system, consisting of train, light rail transport, bus, minibus, ship and seabus, is inadequate and most commuters prefer to drive their private cars. Car ownership is on an increase; the first Bosphorus bridge has already reached its capacity; the average daily traffic is around hundred thousand vehicles a day resulting in long waiting times, due to traffic congestion at access and exits of the Bridge.

In order to decrease.traffic congestion a reliable public transport system should be promoted. This situation would discourage the use of private cars on the Bosphorus crossing and encourage the use of public transport.

In a metropolitan area most daily trips can not be made by only one vehicle; commuters have to select a combination of transport modes which are called itineraries in the paper. Transfers from one mode to another have to be made at terminal points which are developed in the city transport system.

Mecidiyeköy is a primary terminal point located on the European side and Pendik is another main terminal in the city transport system which is located on the Anatolian side. Bostanc1 and Kadiköy, Üsküdar are secondary terminals on the Anatolian side, Beşiktaş, Karaköy, Kabataş and Tünel are secondary terminals on the European side.

In this paper, Mecidiyeköy and Pendik have been accepted as origin and destination points for itineraries. Thirty-four alternative itineraries are available between Mecidiyeköy and Pendik. Direct connection is provided only by bus services. The other connections are provided by several transport modes requiring transfers at sub-terminals.

The traffic crossing on the Bosphorus are assumed under free traffic conditions; including all trip types, equal toll fees, no capacity restrictions. The itineraries which connect Mecidiyeköy and Pendik, two major terminal points, are evaluated and prioritized by AHP.

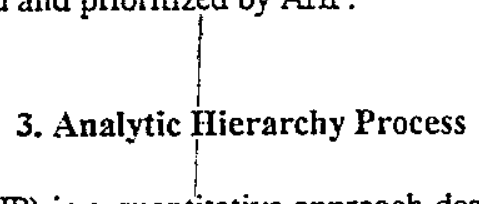

The Analytic Hierarchy Process(AHP) is a quantitative approach designed to handle situations in which subjective judgments are a major part of the decision process(Dyer, 1990). This approach is particularly suitable for selecting among competing alternatives that involve evaluation of multiple criteria.

Typically, the AHP is described in terms of three basic components:(a) design of the hierarchy, (b)the prioritization procedure, and (c)calculation of results. The AHP first breaks down a complex multicriteria decision-making problem into a hierarchy, in which each level is composed of specific elements(Saaty, 1990b). The overall objective of the decision-making process is at the top of the hierarchy, and the criteria, sub-criteria, and decision alternatives are at each descending level of the hierarchy. 


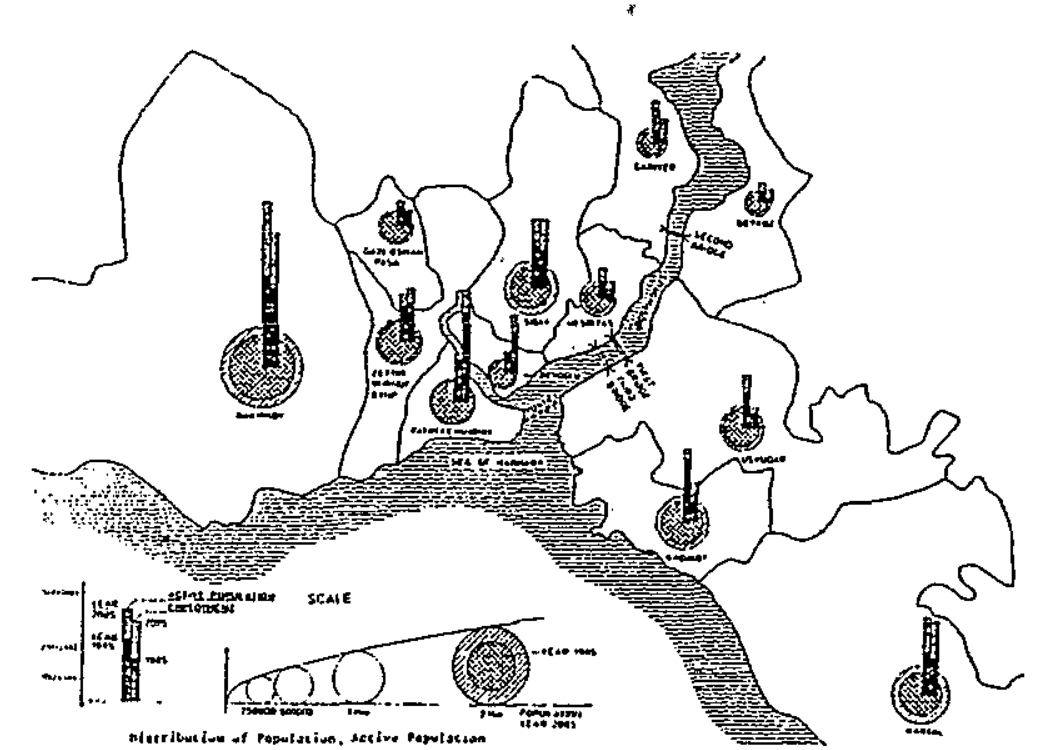

Fig. 2. Distibution of Population, Active Population and Employment (1985-2005) (Imar-Weidleplan, 1994)

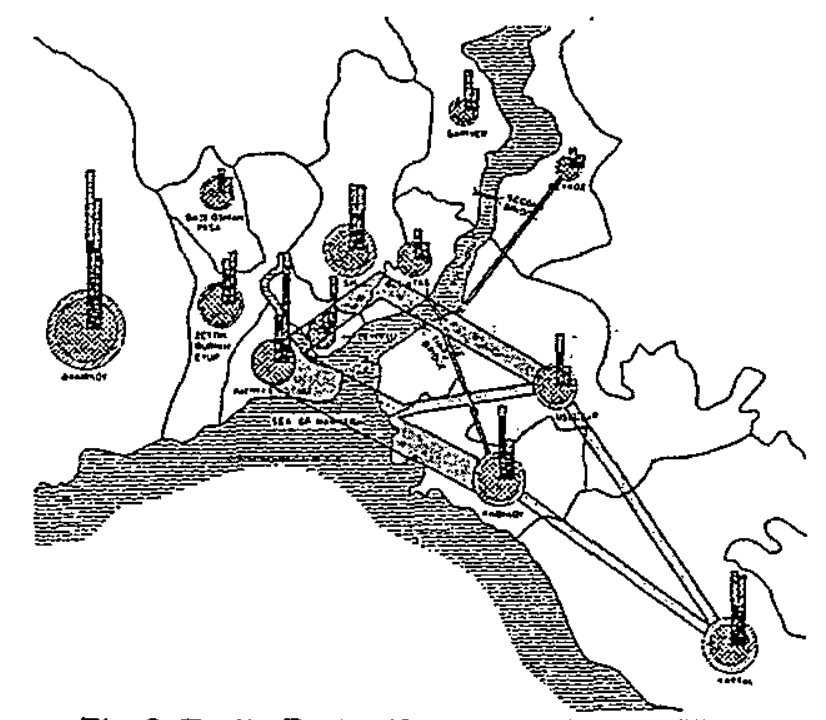

Fig. 3. Traffic Desire (Commuters East to West) (Imar-Weidleplan, 1994) 
Once the hierarchy has been constructed, the decision maker begins the prioritization procedure to determine the relative importance of the elements in each level. Elements in each level are compared pairwise in terms of their.importance to an element in the next higher level.

The nominal scale used for comparisons in AHP enables the decision maker to incorporate experience and knowledge intuitively (Harper and Vargas, 1990). The decision maker can express his preference between every two elements verbally as equally important (or preferred), moderately more important, strongly more important, very strongly more important, or extremely more important. These descriptive preferences would then be translated into numerical ratings $1,3,5,7$ and 9 respectively with $2,4,6$ and 8 as intermediate values for compromises between two successive qualitative judgments(Saaty, 1990a). This scale is insensitive to small changes in a decision maker's preferences, thereby minimizing the effect of uncertainty in evaluations.

After forming the preference matrices, the process moves to deriving relative weights for the various elements. The composite weights of the decision alternatives are determined by aggregating the weights throughout the hierarchy.

Not only does Expert Choice (EC) calculate priorities based on judgements, it also produces a measure of inconsistency (Forman and Saaty, 1993). This measure is useful in identifying possible errors in expressing judgements as well as actual inconsistencies in the judgements themselves. Suggestions can be requested for improving consistency.

Finally, all the comparisons are synthesized to rank the alternatives overall. The result is a set of priorities for the alternatives. AHP serves as an excellent tool for communicating a recommended decision to other levels within an organization (Vargas, 1990).

\section{Determination of Criteria}

Transport authorities who aim to provide the most efficient transportation system for commuters have to consider passenger preferences. It has been accepted that three main criteria have effects on passenger preferences; time, comfort and cost. Distance has been taken as a prosy to confort criterion.

İstanbul commuters are also exposed to air pollution and thus sensitive to this issue. Until recently, Istanbul had been accepted as an environmentally clean city. Little regard was given to the side effects of the transportation vehicles. Since transportation vehicles affect environmental pollution, the transport mode selection has become an important issue. Nowadays, polluted air is one of the main concerns of the municipalities (Envir. Mngt. in Municip., 1995).

The air pollution caused by transportation vehicles is primarily concentrated around the metropolitan areas and urban traffic is one of the main cause. The environmental impact produced by each mode of transportation vary in terms of intensity. Considering the existing situation. in this paper air pollution is taken as a criterion which affects passenger preference.

Time (minute): is the total time spend along the route including waiting time at the terminals.

Terminal waiting time is calculated as: (total time for a round trip $\times 0.05$ ) $\div 3$ minutes.

This calculation has been used by İstanbul Bus Authority in their service amelioration projects (IETT.

1994). Savings in travel time has an important effect on a passenger's decision.

Comfort level of the transport vehicles has an effect on passenger preference.

Cost (TL/passenger): Ticket price paid by each passenger during the trip, including all modes used. 
In İstanbul, public transportation is mostly preferred by low and middle income groups .(IETT, 1994). These groups are quite sensitive to price chances. Travel expense is an important criteria which has high priority on personal itinerary selection.

\section{Air Pollution}

Pollution, as a chemical agent can be quantified and measured as to level and effect. Some transportation sources emit pollutants in relatively large quantities, but all pollutants are not equally harmful. About $70 \%$ of man-made carbon monoxide $(\mathrm{CO})$ is attributed to hightvay vehicles; and $\mathrm{CO}$ comprises a large portion of pollution (Homburger, 1976).

\section{Design of The Hierarchy}

The goal, selected criteria and alternative itineraries are structured in a hierarchical manner. The goal is to prioritize the itineraries. The relevant criteria a re defined in two levels. First level criteria are time, comfort, cost, and air pollution. Air pollution is divided into sulfur dioxide( $\left.\mathrm{SO}_{2}\right)$, carbon monoxide(CO), hydrocarbon(HC) and nitrogen oxide(NO) as sub-criteria.

Data related to time, comfort and cost have been provided from the official records of The State Railways, Istanbul Bus Authority, İstanbul Maritime Lines, İstanbul Seabus Company and the Minibus Association (See Table 1).

Air pollution emissions' are influenced by several factors including power source(steam or diesel), engine size (in kilowatts or hợsepoiver), fuel used (coal, residual oil or diesel oil), operating speed, and load.

In the paper, calculations for àverage émission factors have been based on fuel consumptions of coastal commercial motorships for sea trips and heavy duty diesel powered vehicles for land transportation (Env. Protection Agency, 1973). Since railways are operated by electric energy, they are air pollution free vehicles: Data about fuel consumption have been derived from official records.

Gr/kilometer/ passenger air pollutants have been calculated and then results have been multiplied by distance for each vehicle which has been used in the itinerary. Total air pollution has been calculated for each itinerary per passenger.

\section{Prioritization Procedure}

Since there are thirty-four alternative itineraries, it is not practical to compare each item with all other items in respect to each of the established criteria. The decision maker.must rate the alternatives with respect to each of the criteria. The ratings method for entering judgments is used when the alternatives have been evaluated against standards rather than against each other under all of the subcriteria.

Measurement against a standard is referred to as absolute measurement. This method has the advantage that hundreds of alternatives can be ranked easily. But standards must be well understood and the person who is doing the ratings should be comfortable comparing alternatives against them. This procedure is referred to as the intensity mode of AFP. Expert Choice (EC) labels this procedure the "absolute" mode of AHP. This process has been described by Forman and Saaty (Saaty. 1986). 
TABLE 1

Alternative Itineraries

\begin{tabular}{|c|c|c|c|c|c|c|c|c|}
\hline TTLNEEARY & & $\operatorname{TIME}$ & DISTANCE & $\cos T$ & so, & co & $\mathrm{HC}$ & No \\
\hline ENABB & & 83.0 & 35.00 & 20 & 0.0503 & 5.5560 & 0.9188 & 9,1875 \\
\hline PAM-BB & & 126.0 & 41.00 & 30 & 0.7088 & 6.50008 & $1.07 \$ 3$ & 10.2025 \\
\hline PSTHM-BSB & & 124.4 & 35.40 & 35 & 1.8076 & 9.1497 & 2.7324 & 18,4582 \\
\hline PJWHM-BSMLB & & 127.0 & 34.90 & to & 1.5072 & 8.9752 & 2.7038 & 18.1675 \\
\hline PKBeM-ESB & & 130.0 & 34.83 & 35 & 18903 & 9.6021 & 3.2902 & $2 ! .2471$ \\
\hline PXBeM-BSMBMb & & 122.0 & 3483 & 49 & 2.1705 & 11.0207 & 35293 & 23.7038 \\
\hline FOMA-MBB & & 108.0 & $\$ 1.00$ & $\$ 0$ & 2.7150 & 122306 & 49011 & 24.2472 \\
\hline PKEKM-MbSE & & 104.4 & 35.40 & i5 & $3.55+5$ & $14 \Delta 37 t$ & 0.8172 & 352409 \\
\hline PKKFIM-MbSMTB & & 107.0 & 3490 & 50 & $3.53 \mathrm{4} 2$ & 14.7032 & 6.5024 & 35.6522 \\
\hline FKBEM-MbSB & & 110.0 & $3: 33$ & 45 & 3 S.133 & 15.3301 & 7.1750 & 38.7318 \\
\hline FKBeM-MbSMbMb & & 102.0 & $34 \Delta 3$ & 59 & +.1235 & 16.7577 & $7.73+1$ & $41.2+85$ \\
\hline PKM-TKBB & & 113.6 & $\$ 0.00$ & 40 & 0.3376 & $2 \Delta 575$ & $0 \$ \$ 033$ & 8.0325 \\
\hline FKOKrXY-TrESB & & 113.0 & 3440 & i5 & 1.1708 & 5.49004 & 2.4594 & 15.7282 \\
\hline PKKKMM-TrESMEB & & 115.0 & 33.90 & 50 & 1,1580 & 5.3239 & 2.1300 & $15 . \$ 375$ \\
\hline FHBeM-TrBSB & & 118.0 & 33.53 & 45 & 1.4651 & 5.9508 & 3.0172 & 28.5171 \\
\hline PTBEM.TraSMbSO & & 110.0 & 33.53 & 59 & 1.7453 & 7.3784 & 35763 & 21.0338 \\
\hline PBaM-Bg & & 80,0 & 37.60 & 30 & 0.7049 & 59090 & 0.9670 & 9.870ì \\
\hline FBaLbM.BSbB & & 78.2 & 3.79 & 70 & 0.4245 & 35.0818 & 15.5230 & 85.2302 \\
\hline PBaBeM-BSB & & 101.0 & 3453 & 35 & 4.2451 & 188598 & 7.50004 & 43.9738 \\
\hline PBaBeM-BSMbMb & & 93.0 & $3: 83$ & 49 & $4.52 \approx 3$ & 19.6641 & 6.3655 & 46.4905 \\
\hline FBaKrM-BSbB & & 77.4 & 33.60 & 70 & 6.4545 & 26.0457 & 21.9755 & 06.3932 \\
\hline PBoksM-BSbMtB & $\mathbf{t}$ & 80.0 & 33.07 & 75 & 0.4639 & 275711 & 11.9467 & $08.10+4$ \\
\hline PBaM-MbE & 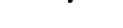 & 79.0 & 37.50 & 40 & 1.533 & 9.2383 & 32330 & 20.0032 \\
\hline PBaKDMM-MUSBB & & 71.2 & 33.79 & 80 & 4.7 .6130 & $38.081 !$ & 17.7750 & 95.3633 \\
\hline PBOBAM-MBSB & & 98.0 & $3+\$ 3$ & 45 & 5.3706 & $22.1789^{\circ}$ & 10.0578 & 5.1089 \\
\hline PBOBEN/MLSMBMb & & $88.0^{\circ}$ & 34.63 & .59 & 5.0523 & 23.0034 & 10.0189 & 56.0236 \\
\hline PBoK"M-MTOSbB & & 70.4 & 33.00 & 60 & 7.6130 & 31.3850 & 14.2289 & 78.5263 \\
\hline PBaKkM-MbSbMLB & & 73.0 & 33.07 & 85 & 7.5924 & $31.1900^{\circ}$ & $* 11.198 \mathrm{t}$ & .78 .2075 \\
\hline FBak-TrB & & 85.0 & $\mathbf{3 7 . 7 0}$ & 30 & 0.4161 & $3.5+11$ & 0.5854 & s 8535 \\
\hline PBokKLM-TSSDE & & $\pi 2$ & 3389 & 70 & 6.1977 & 33.2329 & $15.12200^{\circ}$ & 81.2139 \\
\hline PBoBeM-TrSt: & & $100.0,1:$ & 34.93 & 35 & 3.9613 & $26.4300_{i}^{-}$ & 7.4048 & 39.9575 \\
\hline PBaBeN1-TYSMBMb & & 92.0 & 34.93. & i9 & 4.2415 & 16.2552 & 79039 & -42.4742 \\
\hline 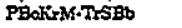 & & 76.4 & $33.70^{\circ}$ & 70 & 6.1977 & 25.8180 & 11.5739 & .02 .3769 \\
\hline PBohiM-TSSbMEB & & 79.0 & 33.17 & 75 & 6.1-3.1 & $25 .+4720$ & $11.5+5\}$. & 62.0681 \\
\hline $\mathbf{p}$ & Peadik & & & & & & & \\
\hline $\mathrm{K}$ & Kisdikö̀y & & & & & & & \\
\hline$M$ & Medidiyekby & & & & & & & \\
\hline 心 & Karaköy & & & & & & & \\
\hline$K b$ & Kabatas & & & & & & & \\
\hline Be & Begiktas & & & & & & & \\
\hline $\begin{array}{l}\text { Bo } \\
B\end{array}$ & $\begin{array}{l}\text { Bootanct } \\
\text { Bus }\end{array}$ & & & & & & & \\
\hline Ab & Minibis & & & & & & & \\
\hline $\mathbf{s}$ & Ship & & & & & & & \\
\hline Sb & Set-bus & & & & & , & & \\
\hline Mt & $\begin{array}{l}\text { Train } \\
\text { Mectoo }\end{array}$ & & & & & " & & \\
\hline
\end{tabular}


In the paper, the rating scale for time criterion uses six intensity levels : 70-80 minutes travel time, 80 90 minutes, $100-110$ minutes, $110-120$ minutes, and $>120$ minutes. The weight of each intensity level has been determined by pairwise comparisons. Questions are asked; such as "in evaluating best itineraries, how much more preferable is $70-80$ minutes travel time than $80-90$ minutes travel time?". The comparision procedure continues as before, and the local weights of these ratings are computed as $.441, .248, .148, .086, .048$, and .029 for 70-80 minutes, 80-90.90-100, 100-110, 110-120, and more than 120 minutes travel times respectively (See Table 2 ).

Comfort and cost criteria are similarly analyzed. For pollution, local priorities of sub criteria $\mathrm{SO}_{2}, \mathrm{CO}$, HC and NO have been calculated by pairwise comparisons. Local priorities have been defined by interviewing Dr.Kadir Alp, Depertment of Environmental Engineering, İstanbul Technical University, whose specialty is air pollution.

\begin{tabular}{lllll}
\multicolumn{5}{c}{ Comparison matrix is given as follows: } \\
\multicolumn{1}{c}{$\mathrm{SO}_{2}$} & $\mathrm{CO}$ & $\mathrm{HC}$ & $\mathrm{NO}$ \\
$\mathrm{SO}_{2}$ & 1 & $1 / 9$ & $1 / 5$ & $1 / 5$ \\
$\mathrm{CO}$ & 9 & 1 & 1 & 2 \\
$\mathrm{HC}$ & 5 & 1 & 1 & 1 \\
$\mathrm{NO}$ & 5 & $1 / 2$ & 1 & 1
\end{tabular}

In $\mathrm{SO}_{2}$ column "9" shows that $\mathrm{CO}$ is extremely more pollutant than $\mathrm{SO}_{2}$, the first " 5 " indicates that $\mathrm{HC}$ is strongly more pollutant than $\mathrm{SO}_{2}$; in hydrocarbon column the first " 1 " shows that $\mathrm{CO}$ and $\mathrm{HC}$ pollute the air equally. The priorities calculated by EC based on importance which given above, are $.05, .407$, .296 , and .246 for $\mathrm{SO}_{2}, \mathrm{CO}, \mathrm{HC}$, and NO sub criteria respectively ..

Seven intensity levels of $\mathrm{SO}_{2}$ and weights of these ratings are shown in Table 3 . They are calculated by $\mathrm{EC}$ in a similar way to them which has been described for time criterion. Intensity levels of $\mathrm{CO}, \mathrm{HC}$ and NO sub-criteria are similarly interpreted.

Before we insert the thirty-four alternatives to be ranked by EC, we need to specify the importance of first level criteria; time, comfort, cost and pollution?

Importance comparison of the first level criteria; time, comfort, cost and pollution has been defined by interviewing passengers. Students from the Faculty of Architecture interviewed the passengers at the terminal points. Comparison matrices have been formed according to their preferences. Emission factor calculations are based on fuel consumption of each transport mode(gr/passenger).

\begin{tabular}{lccc|c} 
& Time & Comfort & Cost & Pollution \\
Time & 1 & 5 & 3 & $1 / 3$ \\
Comfort & $1 / 5$ & 1 & $1 / 3$ & $1 / 7$ \\
Cost & $1 / 3$ & 3 & 1 & $1 / 5$ \\
Pollution & 3 & 7 & 5 & 1
\end{tabular}

In forming this matrix it has been assumed that transport authorities want to satisfy public expectations, therefore passenger preferences have been taken into consideration. In addition, it is assumed that each passenger would support environmentally safe invèstments.

In the pollution row, "3" shows that pollution is moderately more important than transport time; "7" indicates that pollution is very strongly more important than comfort; and pollution is strongly more important than cost. Under the comfort column, / time is strongly more important than comfort; cost is 


\section{TABLE 2}

\section{Criteria and Intensity Levels}

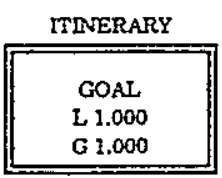

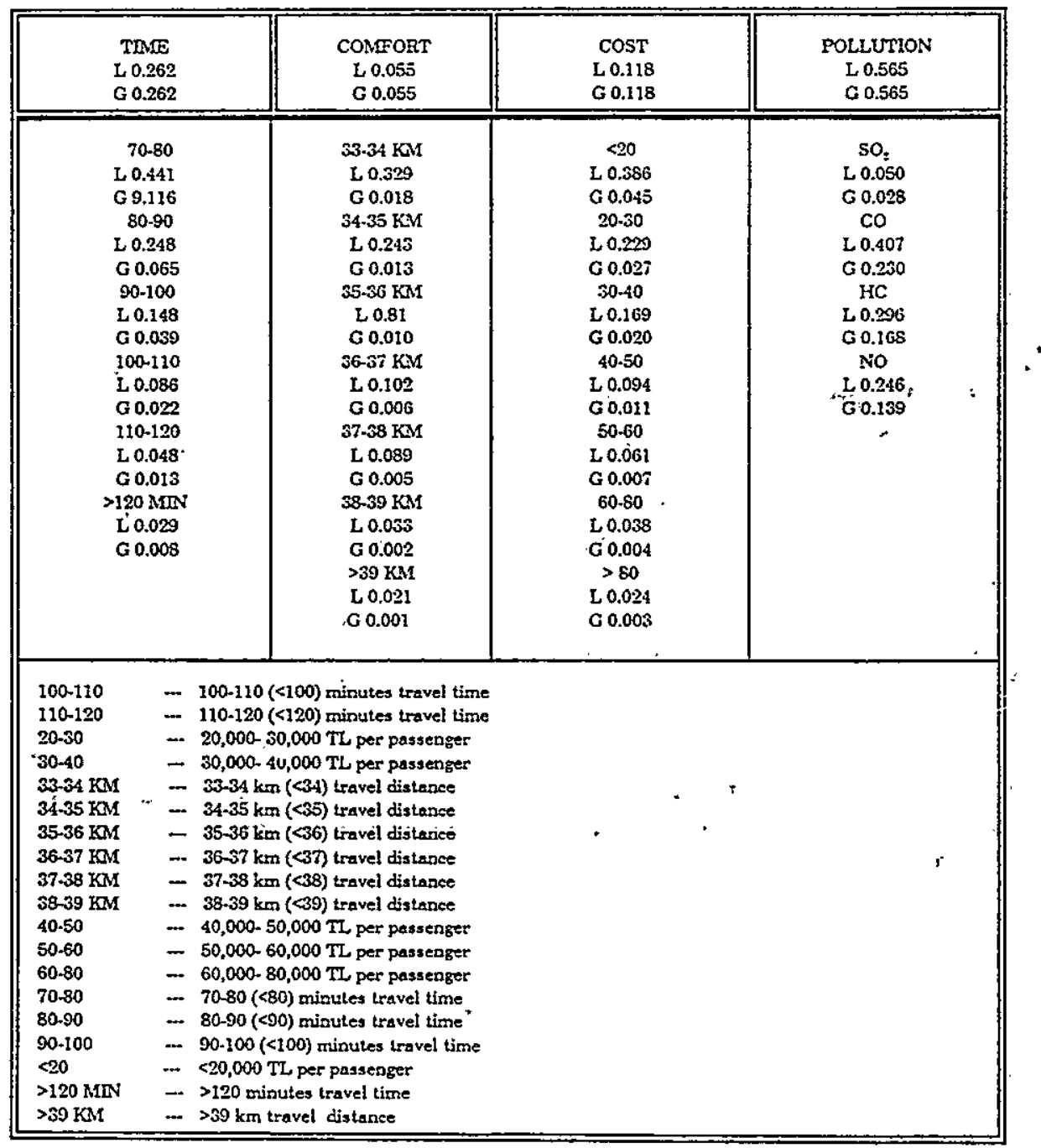


TABLE 3

Subcriteria of Pollution and Intensity Levels

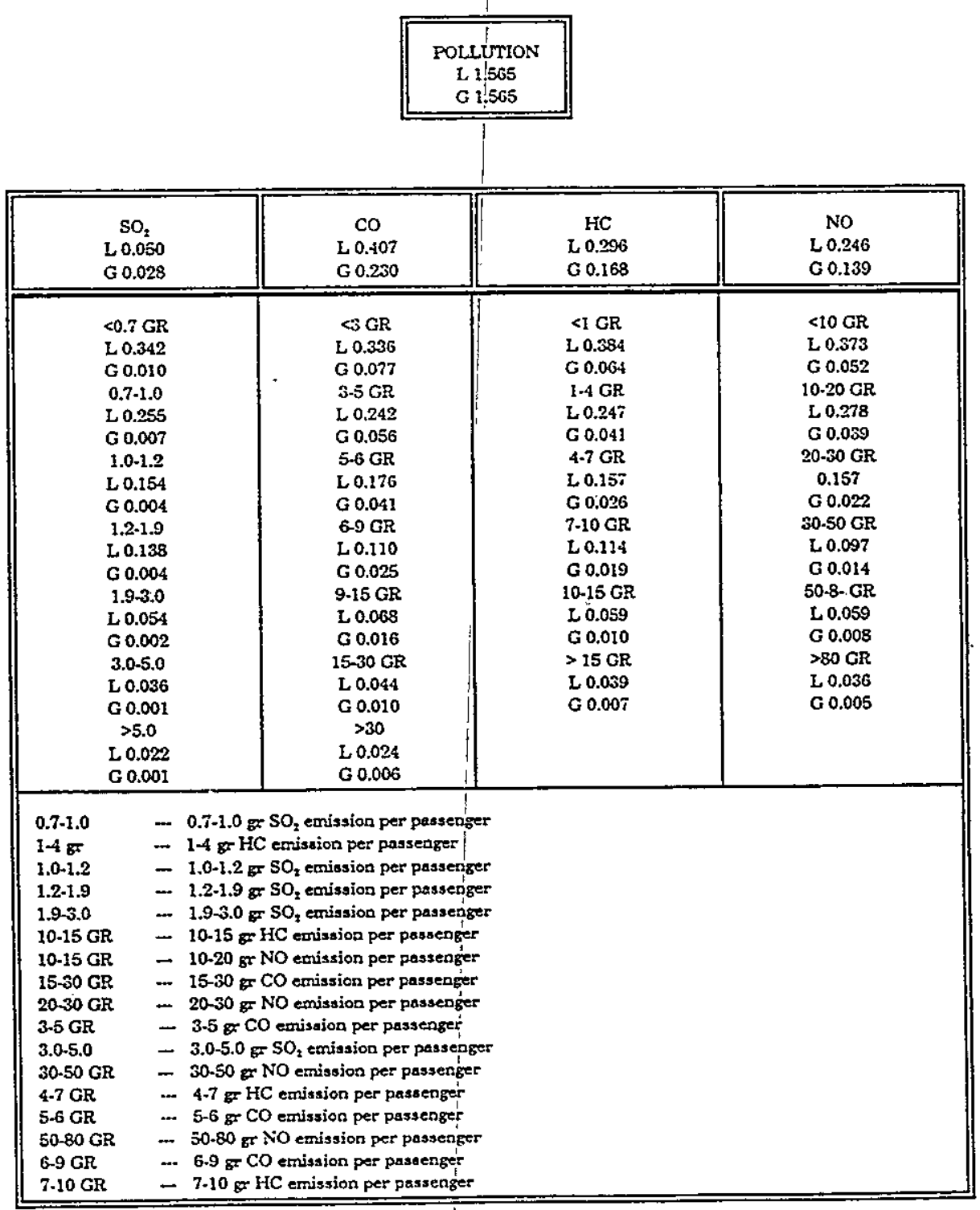


moderately more important and pollution is very strongly more important than comfort in itinerary selections.

\section{Results:}

In the last stage, thirty-four alternative itineraries have been inserted in the EC ratings spreadsheet and results are derived (See Table 4 ).

The best itinerary is :

"Pendik-Mecidiyeköy by bus" (Alternative 1)

Other alternatives in decreasing order of importance are as follows:

"Pendik-Bostanc1-Mecidiyeköy by train and bus"

"Pendik-Bostanc1-Mecidiyeköy by bus and bus"

(Alternative 29)

"Pendik-Kadıköy-Mecidiyeköy by train, bus and bus"

(Alternative 17)

"Pendik-Bostanc1-Mecidiyeköy by minibus and bus"

(Alternative 12)

(Alternative. 23)

\section{Conclusion and Suggestions}

This paper presents an application of the EC in the Istanbul transportation system. It is intended to evaluate the viability of alternatives towards ameliorating the cross-Bosphorus public transport services. Examining passenger preference provides local authorities with data upon which to base their traffic decisions.. Since transportation problems have a multifaceted character, the EC provides a very useful framework for planners and also decision makers.

Results indicate that peripheral itineraries have higher priorities. It has to be taken into account that degree of uncertainty has an effect on the preferences; services which are operated by timetable display higher priorities. Those transport modes which provide service frequency with a moderate comfort level and less environmental pollution have priorities.

In the Istanbul Metropolitan area the rail and the sea transportion services are inefficient. The municipality aims to improve maritime lines. The results of this study, however, reveal that bus and minibus services with the nature of flexible timetables, itinerary changes, and frequent stops are more atractive for passengers. Also, squaiter settlements along the periphery stimulate the demand for minibus and bus services.

If the sea and the railroad services are improved, these changes. would have an effect on passenger preferences. Therefore, comfort levels of each transport mode should be considered in the local government decision making. As passenger life standards change, this change will find its reflections in the passenger preferences. EC will provide this flexibility and will bring new results for each new situation. 
TABLE 4

Prioritization of Itineraries

\begin{tabular}{|c|c|c|c|c|c|c|c|c|}
\hline & Tine & Comfert & Cont & $\begin{array}{l}\text { Pollution } \\
\mathrm{SO}_{2}\end{array}$ & $\begin{array}{l}\text { Pollution } \\
\text { co }\end{array}$ & $\begin{array}{l}\text { Pollution } \\
\text { HC }\end{array}$ & $\begin{array}{l}\text { Pollution } \\
\text { No }\end{array}$ & \\
\hline Alternatives & 0.2022 & 0.0553 & 0.1175 & 0.0255 & 0.2299 & 0.1675 & 0.1391 & Toes] \\
\hline 1 PM:B & $80-90$ & $34.35 \mathrm{kM}$ & $<20$ & $<0.7 \mathrm{GR}$ & 5-8GR & $<1 G R$ & $<10 G R$ & 0.701 \\
\hline 2 FKM-BB & $>120 \mathrm{MIN}$ & $>39 \mathrm{KM}$ & 20.30 & $0.7 \cdot 1.0$ & $0.9 \mathrm{GR}$ & $1-4 G R$ & $10.20 \mathrm{GR}$ & 0.356 \\
\hline 3 PKKrM-BSB & $>120 \mathrm{MtN}$ & $35.30 \mathrm{KM}$ & $30-10$ & $1.2+1.9$ & 9.15GR & $1 \rightarrow G R$ & $10.20 \mathrm{GR}$ & 0.369 \\
\hline 4 PLSFiM-BSMtbB & $>120 \mathrm{MON}$ & $34-35 \mathrm{kM}$ & $30 \rightarrow 0$ & 1.2 .19 & $6.9 \mathrm{GR}$ & $104 \mathrm{GR}$ & $10.20 \mathrm{GR}$ & 0,408 \\
\hline 5 PKBE-BSA & $>120 \mathrm{MIN}$ & $34.35 \mathrm{LM}$ & 3040 & $19-3.0$ & $9.15 \mathrm{GR}$ & $I-G G R$ & $20-30 \mathrm{GR}$ & 0.334 \\
\hline 6 PKBEMSESMLMB & $>120 \mathrm{MN}$ & $34.35 \mathrm{KM}$ & $\$ 0.50$ & 1.9 .3 .0 & $9-15 G R$ & lHGR & $20.30 \mathrm{CR}$ & 0.304 \\
\hline 7 PKM-MbB & $100-110$ & $>39 \mathrm{KM}$ & $30-10$ & $1.9-3.0$ & $9.15 G R$ & HAGR & $20-30 \mathrm{GR}$ & 0.254 \\
\hline 8 PITKRM-MbSE & 100.110 & $35-36 \mathrm{kM}$ & $40-50$ & $3.0-5.0$ & $9-15 \mathrm{CR}$ & 4.7GR & $30.50 G R$ & 0.265 \\
\hline 9 PHEHAM-MBSMtB & $100-110$ & $34.35 \mathrm{KM}$ & 40.50 & 3.0 .5 .0 & 2-1SOR & H.FGR & $30.50 \mathrm{CR}$ & 0.275 \\
\hline 10 PKBEM-MBSB & 100.110 & $34-35 \mathrm{kM}$ & $40-50$ & $3.0-5.0$ & $15-30 G R$ & $\mathrm{TH} 10 \mathrm{GR}$ & $30.50 \mathrm{GR}$ & 0.24 \\
\hline II FHBEM-MbSMbMb & $100-110$ & $34.35 \% \mathrm{M}$ & 50.60 & 3.0 .5 .0 & $15.30 G R$ & $7.10 \mathrm{CR}$ & $30-500 R$ & 0.229 \\
\hline 12 PXM-TYBB & $110-120$ & $>39 \mathrm{KM}$ & $30-10$ & $<0 . \pi \mathrm{GR}$ & $<3 G R$ & $<1 G R$ & $<10 G R$ & 0.648 \\
\hline 13 FK'KXM-TrESB & $110-120$ & $3+35 k a t$ & 40.50 & 1.0 .1 .2 & $5.6 G R$ & 1 HGR & $10-20 \mathrm{CR}$ & 0.143 \\
\hline 14 FKH'M-TrESMEB & $110-120$ & $33-3+\mathrm{KM}$ & +0.50 & $1.0-1.2$ & S. EGR & IfGR & $10.20 \mathrm{GR}$ & 0.457 \\
\hline 15 PKBeM-TKESB & $110-120$ & $33-34 \mathrm{KMI}$ & 40.50 & $1.2-1.9$ & 5.8GR & $1+G R$ & $10-20 \mathrm{GR}$ & 0,458 \\
\hline $16 \mathrm{FKBeM}-\mathrm{TrSMbMb}$ & $110-120$ & $33-345 \mathrm{~K}$ & $50-60$ & 1.2 .1 .9 & $6.9 \mathrm{GR}$ & $1-4 G R$ & $20-30 \mathrm{GR}$ & 0.355 \\
\hline 17 PBOM-BB & $80-90$ & $37-38 \mathrm{sin}$ & $20-30$ & $0.7 \cdot 1.0$ & 5-6GR & $\angle 1 G R$ & $\angle 1 O G R$ & 0.88 \\
\hline 15 PBoKboM-EsbB & $70-60$ & 33-34Кस & $50-80$ & 25.0 & $\angle 30 \mathrm{GR}$ & $>15 G R$ & $>80 G R$ & 0.376 \\
\hline I9 FBOBEM-BSB & $100-110$ & $34-35 \mathrm{KM}$ & $30-40$ & $3.0-5.0$ & $15-30 \mathrm{CR}$ & $\mathrm{i}-10 \mathrm{CR}$ & $30-50 G R$ & 0.202 \\
\hline 20 PAOBEM-ESMDMB & $90-100$ & $34-35 \mathrm{kM}$ & $40.50 !$ & $3.0-5.0$ & $15-30 \mathrm{GR}$ & $7-10 G R$ & SO.SOCR & 0.262 \\
\hline 27 FBoKi-M-BSbB & $70-80$ & 3З-अКस & $80-80$ & $>5.0$ & 15-30GR & $10-15 \mathrm{CR}$ & $50-30 \mathrm{GR}$ & 0.409 \\
\hline 22 PBoKM-BSbMtS & 70.50 & $33-34 \mathrm{KM}$ & $60-80^{\prime}$ & $>5.0$ & 15-30GR & $10.15 G R$ & SO-BOGR & 0.409 \\
\hline 23 PBOM-MbB & $70-60$ & $37.38 \mathrm{KM}$ & $30-40$ & 1.2.1.9 & $9.15 \mathrm{GR}$ & $I-G R$ & $30-30 \mathrm{KR}$ & 0.553 \\
\hline 24 PBOLOM-MbSbB & $70-80$ & 33-3H10M & 60.50 & $>5.0$ & $>30 G R$ & $>15 G R$ & $\triangle \$ O C R$ & 0.378 \\
\hline 25 PBOBCM-MBSB & $90-100$ & $34.35 \mathrm{KM}$ & 40.50 & $>5.0$ & $15-30 \mathrm{CR}$ & $10.15 G R$ & SO-60GR & 0.237 \\
\hline $26 \mathrm{~PB} \circ \mathrm{B} e \mathrm{M} \cdot \mathrm{MBSMBMD}$ & $80-90$ & $34.3512 \mathrm{M}$ & 50.60 & $>5.0$ & 15.30GR & 10.1SGR & $50-50 C R$ & 0.258 \\
\hline 27 PBaKrM-MBSDMLA & 70.80 & $33-34 \mathrm{KM}$ & 60.80 & $>5.0$ & $330 \mathrm{GR}$ & 10.15GR & SO-SOGR & 0.395 \\
\hline 28 FBoK-M-MbSbMtB & $70-80$ & $33-345 a 1$ & $>80$ & $>5.0$ & $>30 G R$ & $10-15 \mathrm{GR}$ & 50-80GR & 0.391 \\
\hline 29 PBOM-THB & $80-90$ & $37.386 \mathrm{M}$ & $20-30:$ & $C 0.7 \mathrm{GR}$ & $3.5 \mathrm{GR}$ & CIGR & $\angle 10 G R$ & 0.733 \\
\hline 30 FBaKbal-TLSbB & 70.80 & $33-34 \mathrm{KM}$ & $\infty 0-80:$ & $>5.0$ & $>30 G R$ & $>15 G R$ & $>B O C R$ & 0.378 \\
\hline 31 PBoBeM-MSB & $90-100$ & $34.35 \mathrm{KMI}$ & $30-10$ & 3.0 .5 .0 & $15-30 G R$ & $7 \cdot 10 \mathrm{GR}$ & $30.500 R$ & 0.299 \\
\hline 32 PBaBeM-TrSMbMb & $90-100$ & $34-35 \mathrm{KOM}$ & 40-50: & $3.0-5.0$ & I5-30GR & $T-10 G R$ & $-20.50 \mathrm{GR}$ & 0.277 \\
\hline 33 PEoKrM-TYSbB & $70-80$ & $33-315 M$ & $60-80:$ & $>5.0$ & 15-30GR & $10-15 \mathrm{GR}$ & 50.50GR & 0.409 \\
\hline 36 PBok-M-TSbMLB & $70-80$ & $33-3+1 \mathrm{kM}$ & $60-60$ & $>5.0$ & $15-30 \mathrm{GR}$ & $10.15 G R$ & SO-80GR & 0.409 \\
\hline
\end{tabular}




\section{References}

Belediyelerde Çevre Yönetimi (Environmental Management in :Lunicipalities). Marmara ve Boğazları Belediyeler Birliği, Mart 1995.p.j.

Compilation of Air Pollutant Emission Factors (Second edition), U.S. Environmental Protection Agency, North Caroline, 1973.

Dökmeci, V., L.Berköz, "Transformation of İstanbul from a Monocentric to a Polycentric City", European Planning Studies, Vol.2, No.2, 1994, pp. 189-201.

Dyer J.S. "Remarks on the Analytic Hierarchy Process", Management Science, 36, 1990 , pp.249-258.

Forman, E.and T.L.Saaty, Expert Choice: Software Package for Personal Computers, Expert Choice, Inc.4922 Elsworth Avenue, Pittsburgh, PA 15213, 1993, p.51.

Harper P.T., L.G.Vargas, Reply to "Remarks on the Analytic Hierarchy Process", Management Science, 36, 1990, pp. 269-273.

Homburger, W.S.(ed.),Transportation and Traffic Engineering Handbook, (Second Edition), Institute of Transport Engineers, Prentice Hall, London, 1976, p.381.

IETT (Istanbul Bus Authority) Official Records, 1994.

Imar-Weidleplan, Bosphorus Crossing by Third Bridge and Tunnel, Prefeasibility Study Report, İstanbul Metropolitan Municipality, İstanbul 1994.

İstanbul Master Plan, İstanbul Metropoliten Municipality, İstanbul. 1995.

Kilınçaslan, T., "Maritime Transportation in İstanbul Metropoliten Area", Making Cities Livable, (Catalogue of Paper Summaries), Feriburg, Germany, 1995.

Saaty, T.L., "Axiomatic Foundations of the Analytic Hierarchy Process", Management Science, 32, 1986, pp.841-855.

Saaty, T.L., "How to Make a Decision: The Analytic Hierarchy Process", European Journal of Operational Research, 48, 1990, pp.9-26.

Saaty, T.L. The Analytic Hierarchy Process. McGraw-Hill. New York 1980. RWS Publications, 4922 Elswoth Avenue, Pittsburg, PA 15213, 1990.

Ülengin, F., "Easing the Traffic in Istanbul", Journal of Operation Research Society, Vol.45, No.7, 1994, pp.77I-785.

Vargas, 1.G. "An Overview of the Analytic Hierarchy Process and its Applications". European Journal of Operational Research,48,1990. pp.2-8. 